\title{
Taller creativo Albufera 2112
}

Máster Proyectos XXI De la Geometría al espacio construido (UPC)/ Máster Urbanismo Territorio y Paisaje (UPV)

SINOPSIS

Durante una semana de abril se desarrolló en las aulas de la ETSAV de Valencia un workshop propositivo en torno a la Albufera. Se abordó la cuestión territorial desde una doble aproximación, arquitectónica por parte del máster UPC Proyectos XXI y urbanística por parte del máster de Urbanismo Territorio y Paisaje de la UPV. Profesores y alumnos de distinta procedencia compartieron un mismo enfoque proyectual que constituye "per se" una interesante experiencia académica. La intensidad del taller, desarrollado en 5 días de trabajo y la estimulación de la creatividad de las propuestas convivió con las aportaciones de los distintos profesores así como con la precisa descripción del marco urbanístico, geopaisajístico y del contexto socio-económi-
co. ma de trí́ngulo cuyo vértice Norte es la ciudad de Valencia constituye no sólo la referencia cultural de toda la región sino un marco natural único en Europa alrededor del cual habita trabaja y se desplaza más de 1 millon de personas. El futuro de este territorio lagunar único, vacío especular de la ciudad de Valencia, está en juego en los próximos años, y constituye una oportunidad para incidir en nuevos moños, de desarrollo y articulación del territorio. La reflexión sobre la geografía el paisaje y la historia, pero también sobre sistema productivo de la huerta valenciana son los hipótesis sobre las que se asientan las cuatro propuestas que se presentan en esta publicación.

\section{Introducción}

El territorio comprendido entre la ciudad de Valencia, el cordón dunar del Saler, la autopista A7 y en su lado Sur los municipios de Favara, Sueca y Cullera es el marco de este taller creativo. Se trata de un territorio alrededor de una lamina de agua que se ha reducido progresivamente a lo largo de la historia y cuyo futuro constituye todo un reto tanto para su protección como para desarrollar nuevos modos de vida, trabajo y ocupación del teritorio. Si las ciudades se fundaron en torno a nos o enclaves naturales determinados, la metrópoli del futuro y en particular este triángulo valenciano de $35 \mathrm{~km}$ de alura y $10 \mathrm{~km}$ de base puede encontrar un genuino desarrollo en torno a la albufera, como a una escala todavia mayor lo es el "green belt" en Holanda, vacio natural alrededor del cual se sitúan ciudades como Ámsterdam, La Haya, Delft, Rótterdam, Utrecht y Hilversum

Además de esta óptica geométrica, el contexto económico actual y las características del sistema productivo valenciano confluyen en señalar a este territorio como un posible receptor de oportunidades vinculadas a la calidad de vida, la alimentación y a la investigación de actividades limpias. La proximidad y desarrollo de infraestructuras de transporte como el aeropuerto, AVE, o puerto son los vehículos que permitirán el adecuado ensamblaje, accesibilidad y desarrollo de programas extensivos pero integrados.

Si la economía valenciana se ha caracterizado por la importancia de la agricultura, los servicios y el turismo, hoy es imprescindible -y la presente crisis económica lo ha hecho más evidente- incorporar la formación especializada, la investigación científica y el desarrollo, a nuevos modelos económicos. Añadamos que si el clima y el entorno natuSillicon Valley la implantación de polos industriales como y deben aspirar a configurar las propuestas de este taller gramas planteados recientemente como el algunos proIndustrial de la Comunidad Valenciana o Plan Estratégico celencia de la UPV y la Universidad de Valencia son puntos de apoyo posibles de propuestas del workshop.

Objetivos

El taller, como se ha dicho, tiene un claro carácter propositivo y se sitúa más próximo a la utopía de futuros que a la evolución espontánea o al procedimiento urbanístico tradicional de las Administraciones. Se concibe desde la imaginación de este extraordinario territorio en un futuro a largo plazo. La actitud utópica de algunas vanguardias del siglo XX como el futurismo, o de algunos arquitectos como los miembros de Archigram constituye una referencia his torica especialmente adecuada. Este mecanismo persigue,
en fin, el alejamiento de las limitaciones coyunturales y se adecua al formato de taller propuesto.

Con la única limitación del respeto a los valores naturales y ambientales del entorno, se prestó especial atención a tres puntos; el desarrollo de un sistema sostenible de movilidad, una propuesta programática para un tejido productivo y científico innovador, con especial atención a la nueva agricultura y el planteamiento de un tipo de residencia especifico en el entorno de la Albufera, al constituir la reflexión sobre los nuevos modos de habitar del futuro y su proximidad con el trabajo y la naturaleza, uno de los campos de trabajo del arquitecto del futuro. Respecto al programa, la intervención del economista Manuel lllueca señaló entre otros puntos a considerar. la concentración de la inversión pública en la creación de Institutos Tecnológicos y de formación punteros en el mundo en campos próximos a nuestra economía como el Agua, la industria Agroalimentaria, la genética y la seguridad alimentaria u otras iniciativas vinculadas a la Medicina o la nanotecnología o incluso a la música y el arte o al automóvil (aprovechando la proximidad y paisajista Ignacio Díez apuntó conceptos de diseño que tuvieron gran aceptación.
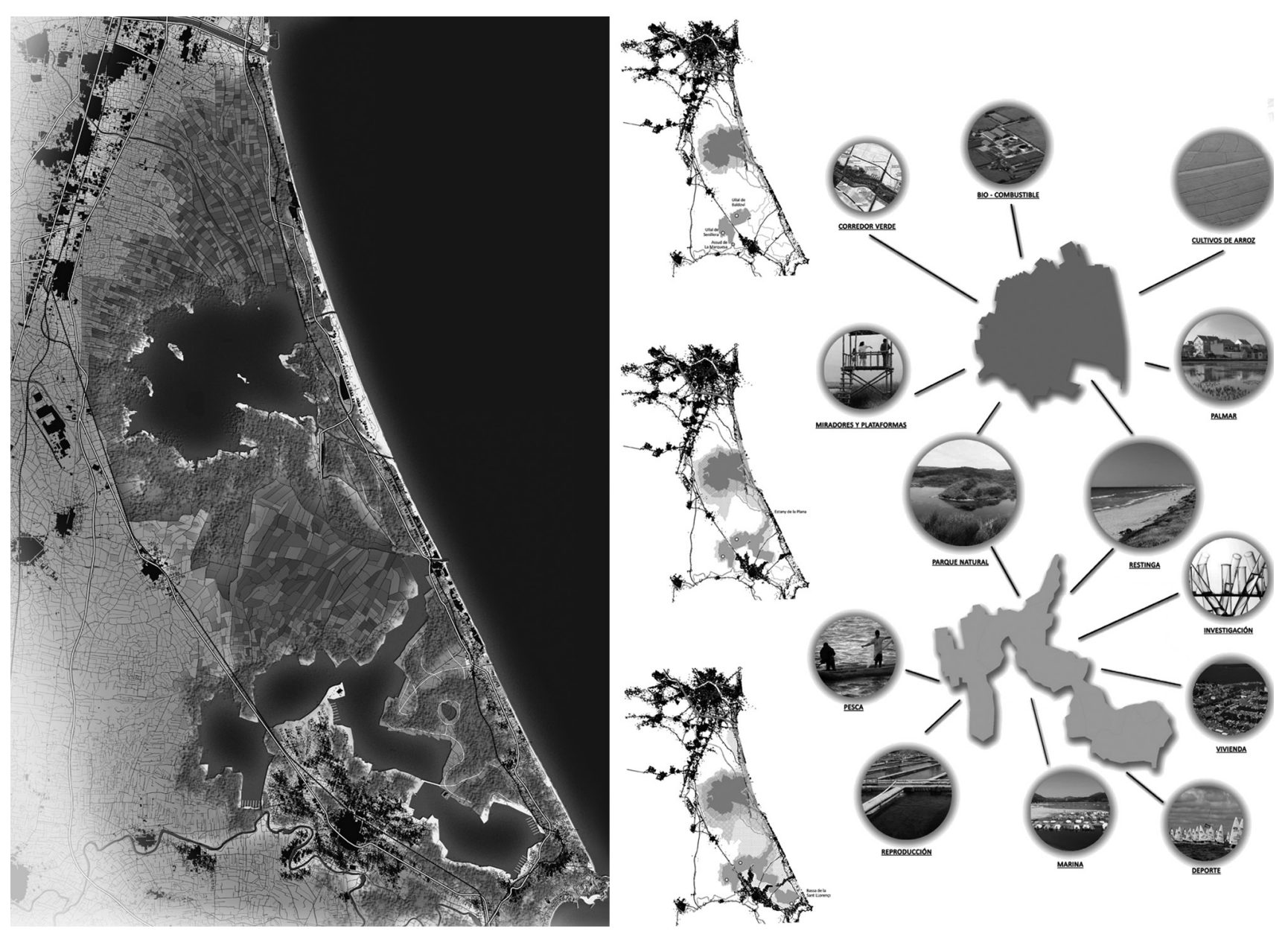

Máster Proyectos XXI de la Geometría al espacio construido (UPC) Carlos Ferrater, Alberto Peñín Llobell, Mara Partida, Jorge Vidal y Roger Such Máster Urbanismo Territorio y Paisaje (UPV)

Alberto Peñín Ibáñez, Javier Pérez Igualada, Angel Martínez Baldó, Antonio Ferrer, Elisabet Quintana, J.Luis Merlo, Santiago Ridocci y Rosario Casao

Profesores Invitados: Ignacio Díez Torrijos (UPV), Manuel Illueca (UJI)
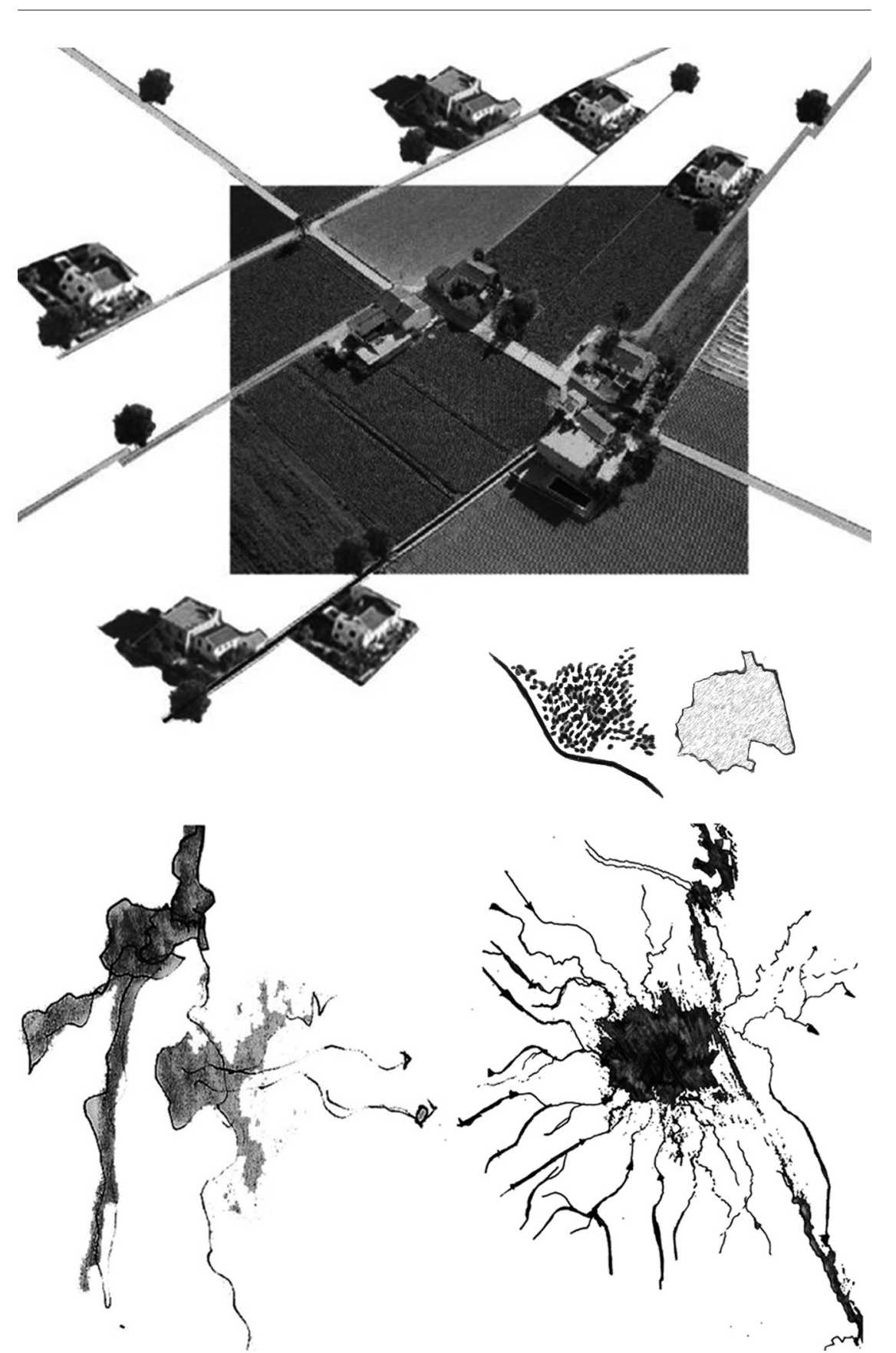

Albufera Bis

La estrategia conservacionista de la lámina de agua existente hoy convive con una radical intervención en la parte Sur del territorio (recreando libremente el antiguo ambito de la laguna), tal y como se ha intervenido en los restos de Altamipara conservarlo y explotar la nueva. Desde el punto de vista metropolitano se apuesta por un reequilibro regional, reaños 20 con el desarrollo arroz y configurándola como la punta de Sur de la Safor. La "construcción" de una nueva lámina de agua se basa en la identificación de manantiales de agua dulce y "ullals" existentes, así como en peonexión con el í Xúquer y la recuperacion de la salida original del lago a mar. El dibujo del nuevo lago permite la especialización programática en distinos sub-vaciós de agua; puertos deportivos, zona de pesca, navegabilidad hasta Sueca, parques de ribera...

Alumnos: Renato Avila, Daniel Reifer, Iñaki Lezaoun, Sebastián Atehortua (UPC) y Víctor Biankouski (UPV)

\section{Green albufera}

La radical naturalización del frente dunar del parque (con supresión de autopista y urbanizaciones) da pie a crear la marca verde de "la albufera". Bajo este sello odo producto fabricado ya fuera en la industria del mueble de la pista de Silla, en a industria del automóvil de Almussafes de la agricultura de Sollana y Sueca cumpliría los requisitos de sostenibilidad en sus materiales y procesos de producción así como en determinados requisios sociales.

En este contexto se subraya la actividad del ecoturismo. El lago se puede entender como un gran hotel gestionado de forma unitaria aunque con diversos explotadores, y que configura el gran dormitorio turistico de la ciudad de Valencia. con los asentamientos históricos del variedad de accesos (por barca desde el puerto, directa desde el aeropuerto) e incluso sus características constructivas (unidades aisladas autosuvo) construyen el elogio de la dispersión a la que la propuesta aspiraba en sus objetivos iniciales.

Alumnos:loula lazou, Tania Cercido, Liao Chia Hsien, Raúl Martínez (UPC) y Jeinmy Ramírez (UPV) tornando a Sueca el protagonismo que una región agrícola que alcanza hasta ficientes y de balance energético positi- 

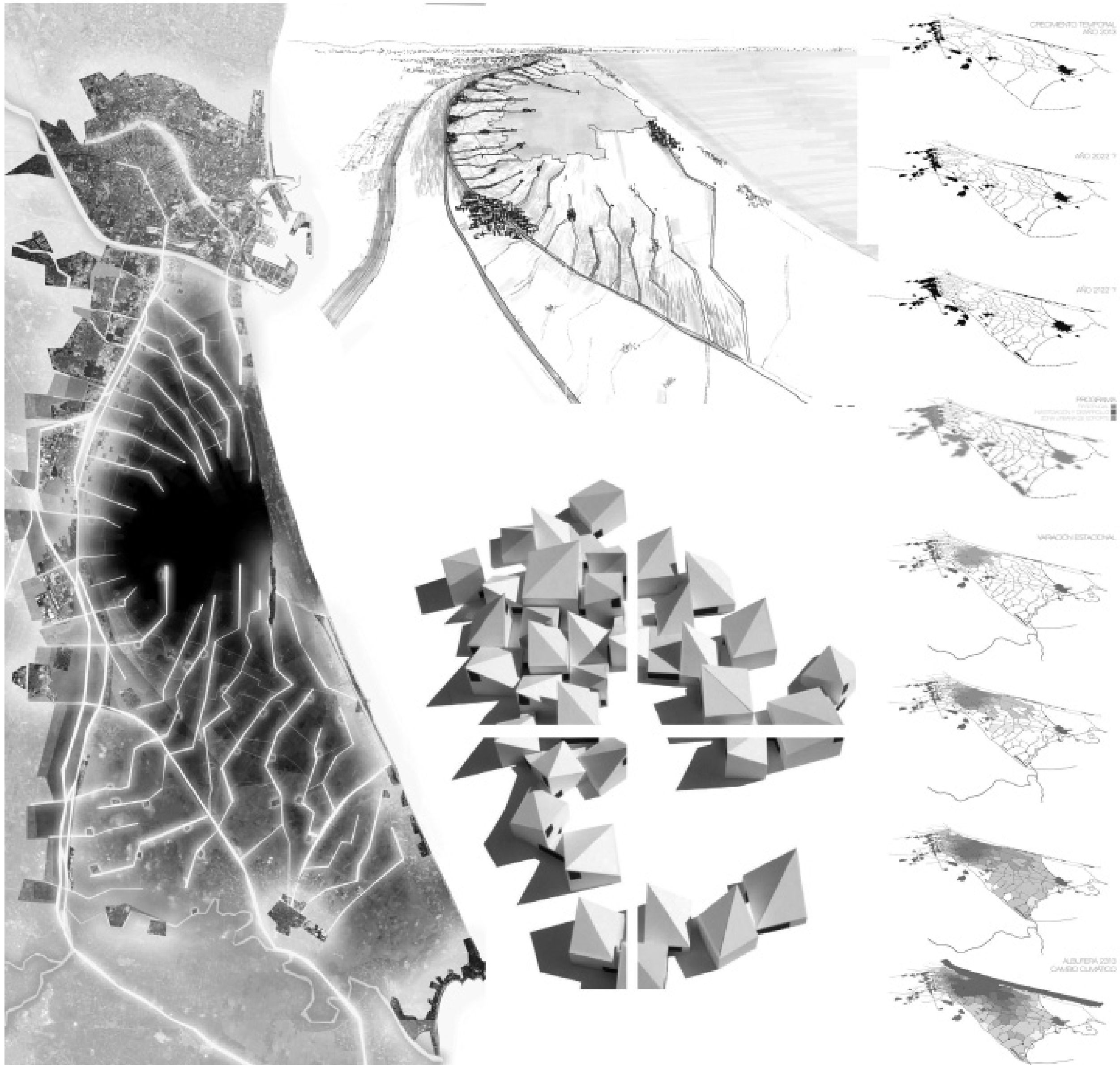

Ecotonizar la Albufera

La propuesta despliega una red capilar a lo largo del Parque inspirada en los amojonamientos que históricamente realizaba el rey para delimitar su territorio. frontera que ecológiy para delimitar su territorio. De esta manera, se estimula la recuperación de los espacios la superficie del parque e integran los futuros niveles de agua debidos al cambio climático.

Esta red capilar se despliega con jerarquía y respeto a las preexistencias. Atienden a las conexiones con los

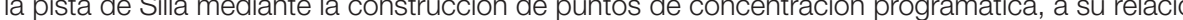
con la restinga (cordón de arena que separa la laguna con el mar) y con la carretera Sollana-Sueca de gran valor paisaijstico. Se propone igualmente la reinterpretación de las tipologías tradicionales y en particular de la barraca valenciana, a través de la creación de pequeños núcleos ubicados de forma dispersa.

Alumnos: Luis Amorós, Fernando Miranda, Marta Montenegro, Furio Gordini (UPC) y Carlos Vercher (UPV)

\section{Balcón a la Albufera}

Con alusiones a Aa operación "Balcón al mar" de la ciudad de Valencia, se identifica mediante el ańlisis de las cotas a parque, una serie de puntos de intervención. Su relación con lo existente favorece la esperión surión de puntos de intervención. Su relación con lo existente favorece respecialización y localización de estos enclaves que se construyen mediante una relativamente sencilla operación de movimiento de tierras. De esta manera se recupera cota para ubicar equipamientos y agricultura, ....y se recupera lámina de agua. La construcción a una escala territorial de puntos estrategicos mediante topografía artificial logra una gran transformación y da sentido productivo a la intervención. Alumnos: Sandra Vicente, Sebastián García, Jorge Muñiz, Alvaro Beruben, Daniela Calandra (UPC)
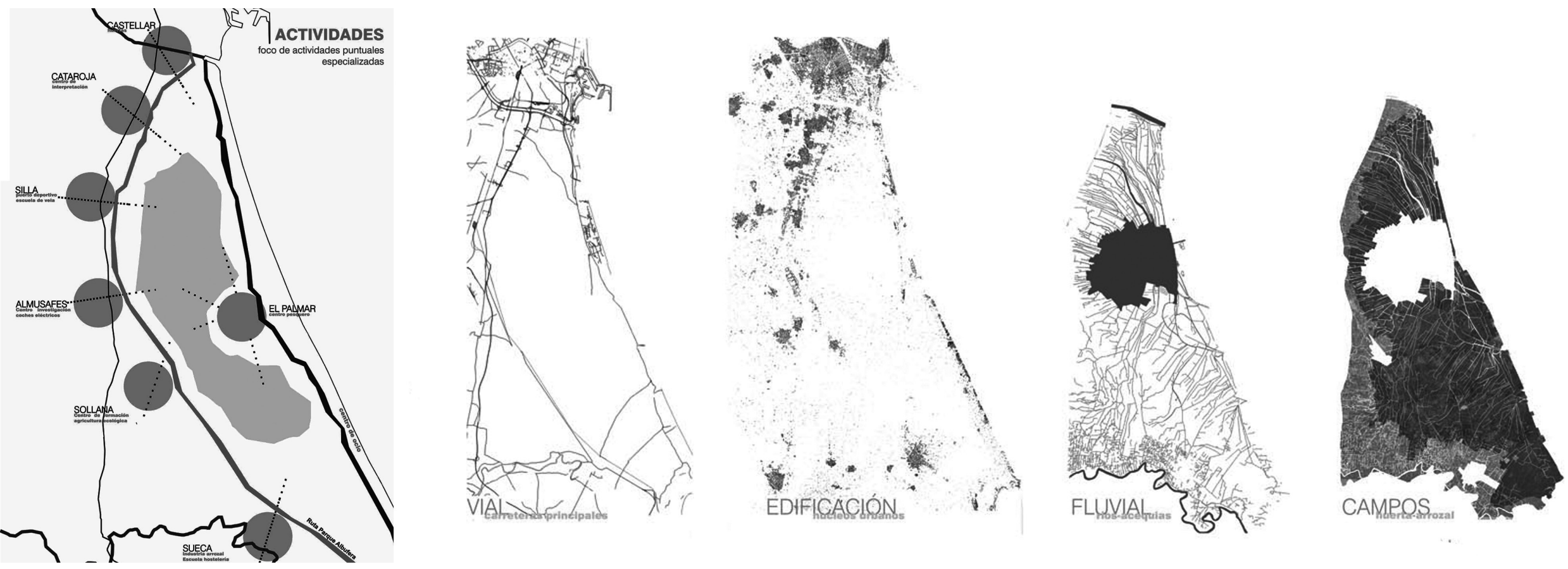